\title{
STUDY OF PALMAR DERMATOGLYPHICS IN SCHIZOPHRENIA
}

\section{Amrita Gupta *1, Anita 2, Subhash Gupta ${ }^{3}$.}

${ }^{1}$ Assistant Professor, Department of Anatomy, Varunarjun Medical College and Research Hospital, Shahjahanpur, UP, India.

${ }^{*}$ Professor and Head, Department of Anatomy, Government Medical College, Bharatpur, Rajasthan, India.

${ }^{3}$ Associate Professor, Department of Anatomy, Varunarjun Medical College and Research Hospital, Shahjahanpur, UP, India.

\section{ABSTRACT}

Background:Dermatoglyphics is the scientific study of epidermal ridges and their configuration on the palmar region of hand and fingers. Development of dermatoglyphic characteristics are under genetic control. This is apparent from the clear similarity in dermatoglyphics among related individuals. There are many diseases known to be caused by abnormal genes. Dermatoglyphic study carried out in Schizophrenia have been evaluated and critically examined.

Materials and methods:The present study included 100 patients of Schizophrenia attending out-patient and inpatient department of Psychiatry at SRMS- IMS Hospital, Bareilly. Similarly equal numbers of paramedical students were included as controls. Individuals with history/ family history of any illnesses were excluded from controls. Dermatoglyphic prints were taken by the modified Purvis method and subjected for detailed dermatoglyphic analysis.

Results:Significant dermatoglyphic findings were observed in Schizophrenics compared to control viz. loops are the predominant patterns and arches are the least found pattern, significant loops in right hand and arches in left hand in females, increased frequency of loop patterns in third and fourth interdigital area $(13,14)$ in Schizophrenics as compared to controls. There is increase inatdangle and lower a-b ridge count, decreased total finger ridge count(TFRC) and absolute finger ridge count(AFRC) and abnormal palmar creases.

Conclusion: Significant findings of dermatoglyphic features were observed in Schizophrenics compared to control group. Dermatoglyphics provide a simple and economical means of assessing the diseases with strong hereditary basis and can be deployed as a screening method for Schizophrenia.

KEYWORDS: Schizophrenia, Dermatoglyphics, Arches, Loops, Whorls.

Corresponding Author: Dr Amrita Gupta, Assistant Professor, Department of Anatomy, Varunarjun Medical College Research Hospital, Shahjahanpur, UP, India.

Mobile no.: +917007423462 E-Mail: ag11677@gmail.com

Access this Article online

Quick Response code

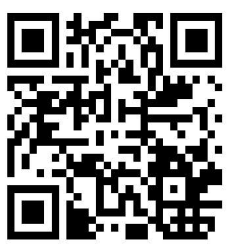

DOI: $10.16965 /$ ijar.2020.156

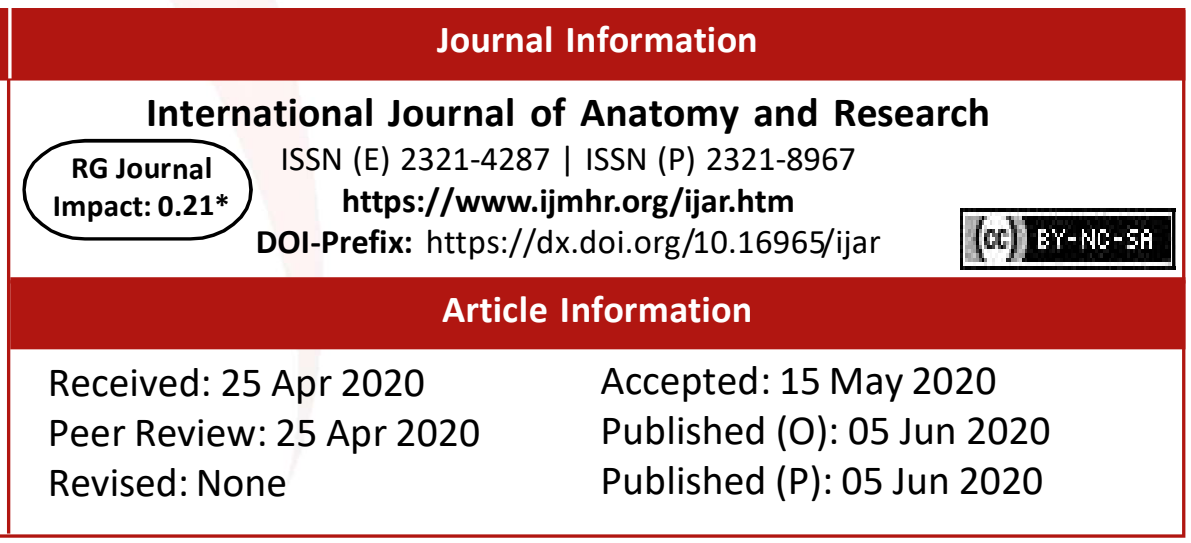

\section{INTRODUCTION}

Dermatoglyphics is the scientific study of epidermal ridges and their configurations on the palmar aspect of hand and fingers. The term dermatoglyphics was coined by Cummins and
Midlo in 1926 and was derived from Greek words 'derma' means skin and 'glyphics' means carvings.The ridge pattern depends on the cornified layer of epidermis and dermal papillae. The typical patterns of epidermal ridges are 
determined since their formation in foetus [1]. The ridges are differentiated during third and fourth month of foetal life and once formed they remain permanent throughout life except in the dimension in proportion to the growth of a person. The original ridge characteristics are not disturbed unless the skin is damaged to a depth of about one millimeter [2].

Development of dermatoglyphic pattern is under genetic control. This is evident from the clear resemblance of dermatoglyphics among related persons. There are many disorders known to be caused by abnormality in genes. When there is any deformity in the genetic makeup of parents it is inherited to the children and is evident in dermatoglyphic pattern [2]. Dermatoglyphics as diagnostic aid is well established in a number of disorders which have a strong hereditary basis, and is employed as a method of screening various diseases.

Although it is used in predicting the diagnosis of genetic diseases, dermatoglyphics is also used in forensic science for individual identification. It is of remarkable use in the field of Physical Anthropology, Human Genetics and Medicine. The research put forth by some scientists suggest that muzzle prints of animals similar to fingerprints in human beings could be used as permanent method of identification to check fraud particularly in insurance issues [3]. Schizophrenia is a clinical entity of variable disruptive psychopathology that involves cognition, emotion, perception, and other aspects of behavior. The display of these manifestations varies individual to individual, but the effect of the illness is severe and usually long lasting. The disorder begins before the age of 25, remains throughout life and it affects individuals of all social strata. Both patients and their family suffer from poor care and social rejectionbecause of widespread ignorance about the disorder. Although often described as a single disease, it comprises of a group of disorders with heterogenous etiologies, and includes patients whose clinical presentations, treatment response, and courses of illness vary [4].

Taking into account the genetic influence of dermatoglyphics and Schizophrenia, the study is done to find out correlation between them, so that dermatoglyphics can be helpful in the diagnosis of predisposition towards these diseases at an earlier age.

\section{MATERIALS AND METHODS}

The present study included 100 patients of Schizophrenia attending out-patient and inpatient department of Psychiatry at SRMS- IMS Hospital, Bareilly, similarly equal numbers of paramedical students were included as controls. Individuals with history/ family history of any illnesses were excluded from controls. Study was carried out with prior permission of institutional ethical committee. Inform consent of all subjects (patients and controls) was taken. Dermatoglyphic prints were taken by the modified Purvis Smith [5] method and subjected for detailed dermatoglyphic analysis. This method was selected from the various methods described in literature because of following advantages:

1. Simple technique.

2. Low cost.

3. Clarity of Prints.

4. Less time consuming.

Materials used for the study include Kores Quick drying duplicating ink, rubber roller, gloves, spirit, A4 size White Bond paper, card board roller, cotton roll, scale, pencil and Pen, protractor To measure 'atd' angle, needle with a sharp point for ridge counting and magnifying lens.

The palm and fingers were printed by the rolling palm technique. A line was drawn from triradii ' $a$ ' to triradii ' $b$ '. Ridge counting was done with the help of a sharp needle and recorded on the same paper with the pencil. The count excludes the ridges forming the triradii. When an accessory triradius ' $a$ ' is present, counting is still done from the ' $a$ ' triradius which is invariably the more radial of the two. Another line was drawn from axial triradius ' $\mathrm{t}$ ' to the digital triradius ' $d$ ' and ' $a$ ' and all the three angles in the triangle were measured using a protractor and recorded.

Parameters observed on palm: For qualitative analysis, the different subtypes of ridge patterns(whorls,loops and arches) were grouped together and were classified and patterns of palmar creases were studied.

Quantitative analysis of finger prints included total finger ridge count(TFRC) and absolute 
finger ridge count(AFRC), a-b ridge count and atd angle.

TFRC represents the sum of ridge counts of all ten digits, where only the larger count is used on those digits with more than one ridge count. It expresses the size of pattern. AFRC is the sum of the ridge counts from all the separate triradii on the fingers. It reflects the pattern size as well as pattern intensity, which depends on the pattern type.

Statistical calculations were done by SPSS v17.0. $P$ value is the probability rate at 0.05 level of significance for the corresponding degree of freedom.

$\mathrm{P}<0.05$ is significant.

Fig. 1: Rolling Palm Technique of taking palm and finger prints.

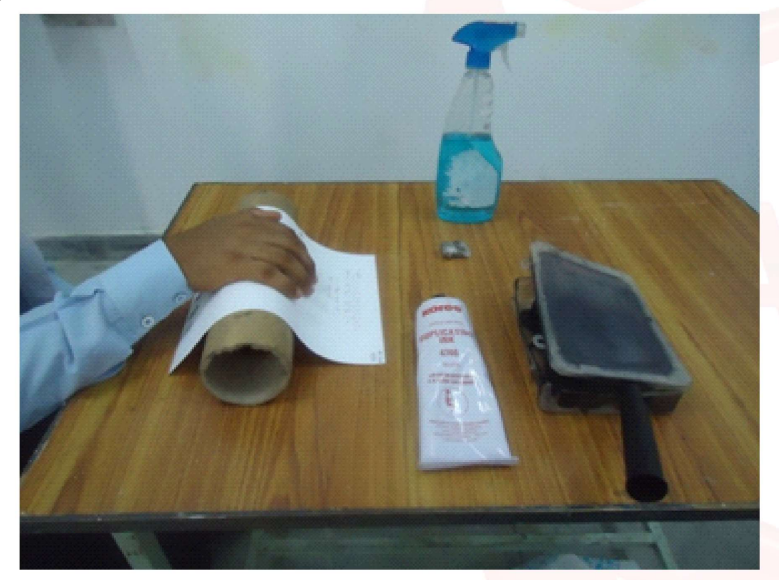

Fig. 2: Showing Palm Print of Right Hand.

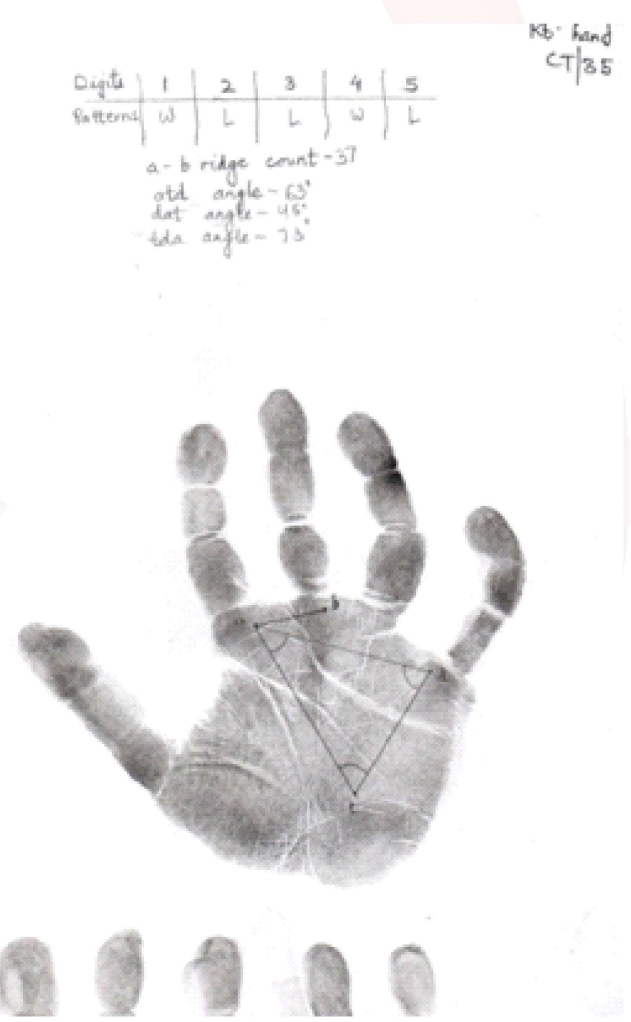

Fig. 3: Showing Palm Print of Left Hand.
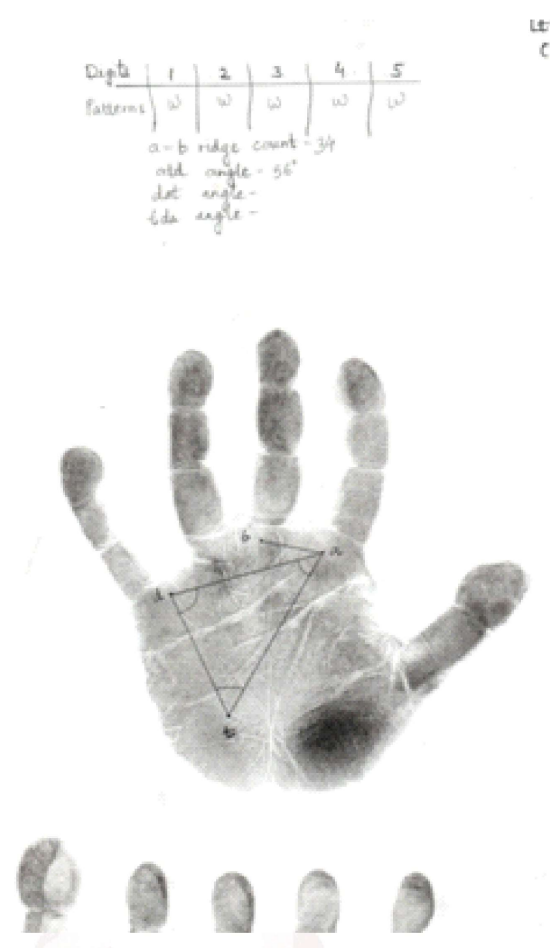

\section{RESULTS AND DISCUSSION}

The dermatoglyphic patterns on right \& left hand of schizophrenics and controls are compared to evaluate significant pattern of identifiable difference between them. 100 schizophrenic subjects ( 50 males and 50 females) and 100 control subjects ( 50 males and 50 females) were taken into consideration for the study.

\section{Qualitative analysis of finger tip patterns}

Table 1: Fingertip Pattern in right and left hand of Schizophrenic patients.

\begin{tabular}{|c|c|c|c|c|}
\hline & Right Hand & Left Hand & Total & P Value \\
\hline Arches & $47(9.1 \%)$ & $54(10.9 \%)$ & $\begin{array}{c}100 \\
(10.0 \%)\end{array}$ & 0.593 \\
\hline Loops & $325(65.1 \%)$ & $289(57.7 \%)$ & $\begin{array}{c}614 \\
(61.4 \%)\end{array}$ & 0.153 \\
\hline Whorls & $128(25.7 \%)$ & $158(31.4 \%)$ & $\begin{array}{c}286 \\
(28.6 \%)\end{array}$ & 0.234 \\
\hline Total & 500 & 500 & 1000 & \\
\hline
\end{tabular}

Table1 shows frequency distribution and statistical comparison of Fingertip patterns in right and left hand of Schizophrenic patients. Loops (61.4\%) are the predominant pattern found in schizophrenics cases but with non significant association and arches (10\%) are the least common pattern present, also with no statistically significant difference. 
Amrita Gupta, Anita, Subhash Gupta. STUDY OF PALMAR DERMATOGLYPHICS IN SCHIZOPHRENIA.

Table 2: Fingertip Pattern in Female and Male Schizophrenic cases.

\begin{tabular}{|c|c|c|c|c|c|c|c|c|}
\hline \multirow{2}{*}{ Pattern } & \multicolumn{4}{|c|}{ Female } & \multicolumn{4}{c|}{ Male } \\
\cline { 2 - 10 } & Right Hand & Left Hand & Total & P Value & Right Hand & Left Hand & Total & P Value \\
\hline Arches & $10(4.0 \%)$ & $65(26.0 \%)$ & $75(15.0 \%)$ & $\mathbf{0 . 0 0 2} \mathbf{S}^{*}$ & $28(11.2 \%)$ & $12(4.8 \%)$ & $40(8.0 \%)$ & 0.062 \\
\hline Loops & $195(78.0 \%)$ & $140(56.0 \%)$ & $335(67.0 \%)$ & $\mathbf{0 . 0 1 9} \mathbf{S}^{*}$ & $150(60.0 \%)$ & $146(58.4 \%)$ & $296(59.2 \%)$ & 0.797 \\
\hline Whorls & $45(18.0 \%)$ & $45(18.0 \%)$ & $90(18.0 \%)$ & 1 & $72(28.8 \%)$ & $92(36.8 \%)$ & $164(32.8 \%)$ & 0.18 \\
\hline Total & 250 & 250 & 500 & & 250 & 250 & 500 & \\
\hline
\end{tabular}

In females, arches (15\%) and loops (67\%) showed statistically significant association $(p<0.05)$ with arches predominating in left hand (26\%) as compared to right hand (4\%). Loops showed increased frequency in right hand (78\%) as compared to left hand (56\%). In males, loops (59.2\%) are the predominant pattern but with non significant association $(p>0.05)$.

Table 3: Finger Tip Patterns in Schizophrenics and Controls in Digits of Hands.

\begin{tabular}{|c|c|c|c|c|c|c|c|c|c|c|c|c|c|}
\hline & \multirow{2}{*}{$\begin{array}{l}\text { Pattern } \\
\text { Group } \\
\end{array}$} & \multicolumn{4}{|c|}{ Arches } & \multicolumn{4}{|c|}{ Loops } & \multicolumn{4}{|c|}{ Whorls } \\
\hline & & Male & Female & Total & $P$ value & Male & Female & Total & $P$ value & Male & Female & Total & $P$ value \\
\hline \multirow{2}{*}{ 1st Digit } & Controls & 13 & 15 & 28 & \multirow{2}{*}{0.56} & 54 & 53 & 107 & \multirow{2}{*}{0.173} & 33 & 32 & 65 & \multirow{2}{*}{0.235} \\
\hline & SCHIZO & 16 & 15 & 31 & & 54 & 51 & 105 & & 30 & 34 & 64 & \\
\hline \multirow{2}{*}{$2^{\text {nd }}$ Digit } & Controls & 18 & 21 & 39 & \multirow{2}{*}{0.493} & 53 & 49 & 102 & \multirow{2}{*}{0.865} & 32 & 27 & 59 & \multirow{2}{*}{0.721} \\
\hline & SCHIZO & 14 & 19 & 33 & & 58 & 46 & 104 & & 28 & 35 & 63 & \\
\hline \multirow{2}{*}{$3^{\text {rd }}$ Digit } & Controls & 16 & 15 & 31 & \multirow{2}{*}{0.07} & 60 & 49 & 109 & \multirow{2}{*}{0.854} & 24 & 36 & 60 & \multirow{2}{*}{0.308} \\
\hline & SCHIZO & 17 & 24 & 41 & & 61 & 47 & 108 & & 22 & 29 & 51 & \\
\hline \multirow{2}{*}{$4^{\text {th }}$ Digit } & Controls & 11 & 13 & 24 & \multirow{2}{*}{0.052} & 64 & 60 & 124 & \multirow{2}{*}{$0.003 \mathrm{~S}$} & 25 & 27 & 52 & \multirow{2}{*}{$0.0001 \mathrm{~s}$} \\
\hline & SCHIZO & 19 & 20 & 39 & & 68 & 62 & 130 & & 13 & 18 & 31 & \\
\hline \multirow{2}{*}{$5^{\text {th }}$ Digit } & Controls & 12 & 12 & 24 & \multirow{2}{*}{0.423} & 64 & 56 & 120 & \multirow{2}{*}{1.000} & 24 & 32 & 56 & \multirow{2}{*}{0.284} \\
\hline & SCHIZO & 11 & 12 & 23 & & 59 & 57 & 116 & & 30 & 31 & 61 & \\
\hline
\end{tabular}

In $1^{\text {st }}$ digit of hands, no statistically significant association $(p>0.05)$ is found for ridge patterns between schizophrenics and controls. Loops and whorls are in equal percentage in controls as compared with schizophrenics in which whorls are commonest pattern followed by loops. Arches are rare on 1st digit both in controls and schizophrenics.

The maximum distribution of whorls and loop were present in the 4 th digit with significant association in schizophrenics.

There is an increased frequency of loop patterns in third and fourth interdigital area $(13,14)$ in schizophrenics as compared to controls. This pattern was obvious in both the sexes $n$ in both hands concomitantly. There was also presence of higher frequency of abnormal palmar creases. There was non significant evidence of presence of simian crease in both males $n$ females irrespective of any hand.

\section{Quantitative Analysis}

Table 4 shows statistical calculation of $a-b$ ridge count in Schizophrenia and controls. The mean value of $a-b$ ridge count in Schizophrenic females is lower in right hand as compared to the controls but statistically non-significant. Left hand shows no significant difference between controls and Schizophrenics.

Table 5 shows statistical calculation of atd angle in Schizophrenics and controls. There is significant increase in the mean value of atd angle in Schizophrenics (mean $=55.60$ ) in right hand of males as compared to the controls (mean=44.43). There is significant increase in the mean value of atd angle in Schizophrenics (mean=46.16) in left hand of males as compared to controls (mean=41.30).

Table 6 shows the mean Total Finger Ridge Count (TFRC) in female Schizophrenics was lesser (129.9) with S.D. of 2.75 as compared to Controls which had mean value(158.8) with S.D. of 2.9 with no statistical significance. The mean Total Finger Ridge Count (TFRC) in male Schizophrenics was also less (132.6) with S.D. of 7.52 as compared to male Controls which had mean value(157.86) with S.D. of 4.81 with no statistical significance.

The mean Absolute Finger Ridge Count (AFRC) 
in female patients was lesser (137.96) with S.D. of 5 as compared to female control group which had AFRC 148 with S.D. of 5.39. This difference was statistically not significant. The Mean Absolute Finger Ridge Count (AFRC) in male patients was also less(133.16) with S.D. of 5.64 as compared to male control group which had AFRC (153.78) with S.D of 5.2. This difference was statistically not significant.

Table 4: Calculation of a-b ridge count in Schizophrenia and Control.

\begin{tabular}{|c|c|c|c|c|c|c|c|c|}
\hline \multirow{3}{*}{ Groups } & \multicolumn{4}{|c|}{ Right Hand } & \multicolumn{4}{|c|}{ Left Hand } \\
\hline & \multicolumn{2}{|c|}{ Female } & \multicolumn{2}{|c|}{ Male } & \multicolumn{2}{|c|}{ Female } & \multicolumn{2}{|c|}{ Male } \\
\hline & Mean \pm SD & $P$ value & Mean \pm SD & $P$ value & Mean \pm SD & $P$ value & Mean \pm SD & $P$ value \\
\hline Control & $38.83 \pm 2.93$ & \multirow{2}{*}{0.82} & $37.86 \pm 4.91$ & \multirow{2}{*}{0.997} & $38.00 \pm 5.69$ & \multirow{2}{*}{1} & $38.78 \pm 5.79$ & \multirow{2}{*}{0.996} \\
\hline Schizophrenia & $29.90 \pm 5.15$ & & $32.60 \pm 7.22$ & & $37.90 \pm 5.09$ & & $38.16 \pm 5.04$ & \\
\hline
\end{tabular}

Table 5: Calculation of atd angle in Schizophrenics and Controls.

\begin{tabular}{|c|c|c|c|c|c|c|c|c|}
\hline \multirow{3}{*}{ Groups } & \multicolumn{4}{|c|}{ RIGHT HAND } & \multicolumn{4}{|c|}{ LEFT HAND } \\
\hline & \multicolumn{2}{|c|}{ Female } & \multicolumn{2}{|c|}{ Male } & \multicolumn{2}{|c|}{ Female } & \multicolumn{2}{|c|}{ Male } \\
\hline & Mean \pm SD & $P$ value & Mean \pm SD & $P$ value & Mean \pm SD & $P$ value & Mean \pm SD & $P$ value \\
\hline Control & $44.17 \pm 6.75$ & \multirow{2}{*}{0.999} & $44.43 \pm 5.89$ & \multirow{2}{*}{$0.016 \mathrm{~S}^{*}$} & $43.50 \pm 4.93$ & \multirow{2}{*}{1.992} & $41.30 \pm 6.19$ & \multirow{2}{*}{$0.011 \mathrm{~S}^{*}$} \\
\hline Schizophrenia & $43.60 \pm 4.14$ & & $55.60 \pm 9.72$ & & $45.40 \pm 7.66$ & & $46.16 \pm 11.00$ & \\
\hline
\end{tabular}

Table 6:Shows statistical calculation of TFRC and AFRC in Schizophrenicsand controls.

\begin{tabular}{|c|c|c|c|c|c|c|c|c|}
\hline \multirow{3}{*}{ Groups } & \multicolumn{4}{|c|}{ TFRC } & \multicolumn{4}{|c|}{ AFRC } \\
\hline & \multicolumn{2}{|c|}{ Female } & \multicolumn{2}{|c|}{ Male } & \multicolumn{2}{|c|}{ Female } & \multicolumn{2}{|c|}{ Male } \\
\hline & Mean \pm SD & $P$ value & Mean \pm SD & $P$ value & Mean \pm SD & $P$ value & Mean \pm SD & $P$ value \\
\hline Control & $158.80 \pm 2.90$ & \multirow{2}{*}{0.729} & $157.86 \pm 4.81$ & \multirow{2}{*}{0.597} & $148.00 \pm 5.39$ & \multirow{2}{*}{1.201} & $153.78 \pm 5.20$ & \multirow{2}{*}{0.892} \\
\hline Schizophrenia & $129.90 \pm 2.75$ & & $132.60 \pm 7.52$ & & $137.96 \pm 5.00$ & & $133.16 \pm 5.64$ & \\
\hline
\end{tabular}

\section{DISCUSSION}

The neurodevelopmental model of schizophrenia proposes that both genetic and environmental factors contribute to structural and functional brain changes in the intrauterine and perinatal periods, as well as in childhood and early adolescence. The significance of dermatoglyphics is not for diagnosis but for prevention by predicting a disease. It is ratherto recognize people with genetic predisposition to develop some diseases.

In the present study we try to establish the relevant palmar dermatoglyphic parameters in the patients of Schizophrenia and whether they can be used not only for early detection of chronic diseases but also in screening and prevention of the disease.

Qualitative Analysis: Loops are the predominant pattern found in schizophrenics cases but with non significant association and arches are the least common pattern present, also with no statistically significant difference. Raphael T. et al [6] and Beckman and Norring [7] reported a higher frequency of whorls in schizophrenics. In the present study, loops are in higher frequency which is contrary to studies of above workers. Our study correlated with studies done by Kemali et al [8] and Mellor [9].

Considering schizophrenic females, both loops and arches show statistical significance in hands. Loops show predominance in right hand but arches show predominance in left hand. In males, loops are predominant but no statistical significant difference is found. Similarly Beckman and Norring [7] reported a higher frequency of whorls in female schizophrenics and an increase in arches in males. Sivkov S. et al [10]found in male schizophrenics there was an increased frequency of whorls and in females there was an increased frequency of arches as compared to controls. Findings of above workers partly agree with our findings but not statistically significant.

Singh [11] had reported significant increase in the frequency of whorls and ulnar loops in 
female schizophrenics and arches and accidentals among male schizophrenics. Findings of Singh correlated with the findings in the present study.

The maximum distribution of whorls and loop were present in the 4th digit with significant association in schizophrenics. Varma SL et al [12]found increased frequency of loops and whorls in all digits in Schizophrenic patients as compared to the controls. Our findings are similar with the findings of above workers.

There is an increased frequency of loop patterns in third and fourth interdigital area $(13,14)$ in schizophrenics as compared to controls in both the sexes $\mathrm{n}$ in both hands. There was also presence of higher frequency of abnormal palmar creases and non significant evidence of simian crease in both males $n$ females irrespective of any hand. Beckman and Norring [7], Mellor [9], Polednak [13]reported increased frequency of loop patterns comparable to our study but certain other researchers found reduced frequency contrary to our study.

\section{Quantitative Analysis:}

The mean value of $a-b$ ridge count in Schizophrenic females is lower in right hand as compared to the controls but statistically nonsignificant. Left hand shows no significant difference between controls and Schizophrenics. Schizophrenics also exhibit non significant decrease in $a-b$ ridge count in the present study. Karmakar et al [14], Sengupta et al[15] and Fearon $P$ et al [16] also found lower $a-b$ ridge count in their study which coincides with findings in our study.

In Schizophrenic cases, there is increase in the mean value of atd angle in the present study. Mellor [9] found mean 'atd' angle was significantly higher in both the sexes, Kemali et al [8] revealed the same result. This confirms to the values found in our study.

The mean Total Finger Ridge Count (TFRC) in female Schizophrenics was lesser as compared to Controls. The mean Total Finger Ridge Count (TFRC) in male Schizophrenics was also less as compared to male Controls with no statistical significance.The mean Absolute Finger Ridge Count (AFRC) in male patients was lesser as compared to male control group. The Mean
Absolute Finger Ridge Count (AFRC) in female patients was also less as compared to female control group. Mellor [9] and Rothhammer et al [17]reported non statistical difference in schizophrenic females and control group. N. N. Laha [18] studied dermatoglyphic traits in schizophrenics and revealed statistically insignificant difference in the mean values of ridge count. Van Oel CJ et al. [19] from Netherlands studied both digital and palmar dermatoglyphic indices between twins discordant for schizophrenia and control twins and found contradictory findings. They showed marginally higher absolute finger ridge counts than control twins.

\section{CONCLUSION}

Dermatoglyphics reflect phylogenetic history of an individual and show variability. It is often a neglected aspect of physical examination, therefore can be used as an important screening procedure. The present study is undertaken with an aim to evaluate dermatoglyphic features in Schizophrenics. The detailed study of palm prints revealed interesting information which was supported by some of the earlier studies like in schizophrenic females both loops and arches show statistical significance in hands, whorls and loop were present in the 4th digit with significant association, increased frequency of loop patterns in third and fourth interdigital area $(13,14)$ in schizophrenics as compared to controls in both the sexes $n$ in both hands, lower $a-b$ ridge count, higher 'atd' angle in males and lower TFRC and AFRC.Our results, however, coincided with the earlier observations of few researchers in palmar dermatoglyphics between schizophrenic patients and normal controls. Thus from the present study, it appears that there do exists a variation in the dermatoglyphic patterns in Schizophrenia. The use of dermatoglyphics as a genetic marker in Schizophrenia can be used as a reliable indicator for the mass screening of high risk people for observation or early detection of Schizophrenia.

\section{ABBREVIATIONS}

13-inetrdigital area 3

14- interdigital area 4

TFRC- total finger ridge count

AFRC- absolute finger ridge count 


\section{Conflicts of Interests: None}

\section{REFERENCES}

[1]. Cummins $\mathrm{H}$ and Midlo. Palmar and plantar epidermal configurations (dermatoglyphics) in European Americans. Am.J. Phys Anthropol., 1926;9:471-502.

[2]. Cummins $\mathrm{H}$ and Midlo. Finger prints of palms and soles. An introduction to dermatoglyphics. 1943; Dovar Pub. INC, New York.

[3]. Tarasiuk SI, Glazko VI, TrofimenkoAL.The muzzle prints and biochemical genetic markers as supplementary breed characteristics in cattle. Article in Russian. 1997;31(4):89.

[4]. Sadock BJ, Synopsis of Psychiatry, $10^{\text {th }}$ Edt., pg 467471.

[5]. Ravindranath $\mathrm{R}$, Thomas IM. Finger ridge count and finger print pattern in maturity onset diabetes mellitus. Indian J Med Sci 1995;49:153-6.

[6]. Raphael T. and Raphael L. G. Fingerprints in Schizophrenia. J. American Medical Association 1962;180(3):215-219.

[7]. Beckman L. and Norring A. Finger and palm prints in schizophrenia. Acta. Genet. (Basel) 1963;13:170.

[8]. Kemali D., Polani N., Polani P. E. and Amati A. A dermatoglyphic study of 219 Italian schizophrenic males. Clinical Genetics 1976;9(1):51-60.

[9]. Mellor C.S. Dermatoglyphics in Schizophrenia Brit. J. Psychiat., 1968;114:1387.

[10]. Sivkov S. and Akabaliev V.Dermatoglyphics in Schizophrenia: qualitative aspects. Folia Med. (Plovdiv). 1998;40(3):44-50.

[11]. Singh S. Dermatoglyphics in Schizophrenia. Acta. Genet. (Basel) 1967;(17):348.

[12]. Varma S. L., Chary T. V., Singh S., Azhar M. Z. and Dharap A. S. Dermatoglyphic in schizophrenic patients. Acta psychiatr. Scand. 1995;91(3):213-215.
[13]. Polednak Anthony P. Dermatoglyphics of Negro Schizophrenic Males. British Journal of Psychiatry 1972;120:397-398.

[14]. Karmakar, B. and Malhotra, K. C. Palmar derma toglyphics in schizophrenia. Paper read in International Symposium on Dermatoglyphics held from Feb., 18-23, 1980, Panjabi University, Patiala, India.

[15]. Sengupta S. and Das S. Bhuyan. Palmar dermatoglyphics in Schizophrenia. Indian J. of Psychiatry. 1995;37(2): 86-90.

[16]. Fearon P., Lane A., Airie M., Scannell J., McGowan A., Byrne M., Cannon M., Cotter D., Murphy P., Cassidy B., Waddington J., Larkin C. and O'Callaghan E. Is reduced dermatoglyphic a-b ridge count a reliable marker of developmental impairment in schizophrenia? Schizophr Res. 2001;50(3): 151-7.

[17]. Rothhammer F., Pereira G., Camousseight A. and Benado M. Dermatoglyphic in Schizophrenic patients. Hum. Hered. 1971; 21: 1198.

[18]. Laha N.N.A study of palmar dermatoglyphics in Schizophrenia. Jr. Asso. Phys. Ind.1979;27:329-333.

[19]. Van Oel CJ., Baare WF., Hulshoff Pol HE., Haag J., Balazs J., Dingemans A., Kahn RS. and Sitskoorn MM. Differentiating between low and high susceptibility to schizophrenia in twins: the significance of dermatoglyphic indices in relation to other determinants of brain development. Schizophr Res. 2001;52(3):181-93.

How to cite this article:

Amrita Gupta, Anita, Subhash Gupta. STUDY OF PALMAR

DERMATOGLYPHICS IN SCHIZOPHRENIA. Int J Anat Res 2020;8(2.3):7550-7556. DOI: 10.16965/ijar.2020.156 